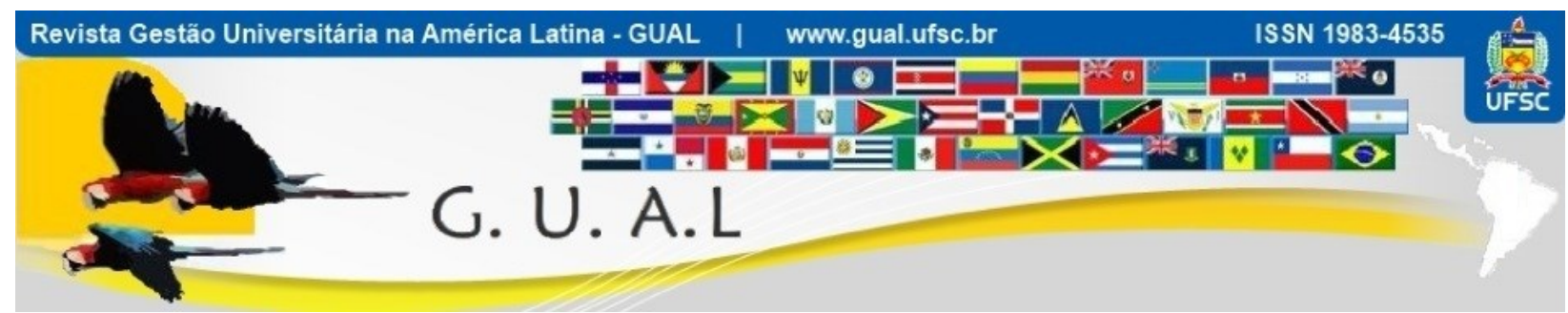

DOI: http://dx.doi.org/10.5007/1983-4535.2019v12n3p106

\title{
O PROGRAMA NACIONAL DE ASSISTÊNCIA ESTUDANTIL - PNAES NA UNIVERSIDADE FEDERAL DE VIÇOSA (UFV): UMA AVALIAÇÃO NA PERCEPÇÃO DOS BENEFICIÁRIOS
}

\author{
THE NATIONAL PROGRAM OF STUDENT ASSISTANCE - PNAES AT \\ UNIVERSIDADE FEDERAL DE VIÇOSA (UFV): AN ASSESSMENT FROM THE \\ BENEFICIARIES' POINT OF VIEW
}

Sueli de Souza Santos Eloi, Graduada https://orcid.org/0000-0001-5113-8745 suelieloi@gmail.com Universidade Federal de Viçosa $\mid$ Departamento de Administração e Contabilidade Viçosa | Minas Gerais | Brasil

Fernanda Cristina da Silva, Doutora http://orcid.org/0000-0002-4384-4997 fernandacsilva.adm@gmail.com Universidade Federal de Viçosa | Departamento de Administração e Contabilidade Viçosa | Minas Gerais | Brasil

Suely de Fátima Ramos Silveira, Doutora https://orcid.org/0000-0002-1303-7190 sramos@ufv.br

Universidade Federal de Viçosa | Programa de Pós-Graduação em Administração Viçosa | Minas Gerais | Brasil

Odemir Vieira Baêta, Doutor https://orcid.org/0000-0002-9855-3599 odemirvieirabaeta@gmail.com Universidade Federal de Viçosa | Departamento de Letras Viçosa | Minas Gerais | Brasil

Recebido em 03/agosto/2018

Aprovado em 04/junho/2019

Publicado em 02/setembro/2019

Sistema de Avaliação: Double Blind Review

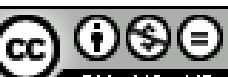

Esta obra está sob uma Licença Creative Commons Atribuição-Uso.

Revista GUAL, Florianópolis, v. 12, n. 3, p. 106-129, setembro-dezembro 2019 www.gual.ufsc.br 


\title{
RESUMO
}

O presente estudo tem por objetivo geral avaliar o Programa Nacional de Assistência Estudantil (PNAES) na Universidade Federal de Viçosa (UFV) na percepção de seus beneficiários. Para tanto, foi realizada uma pesquisa de caráter descritiva, de natureza quantitativa e do tipo levantamento. Os dados foram coletados por meio de questionários aplicados a uma amostra de 312 beneficiários do Programa. Como método de análise, utilizou-se de estatística descritiva. De forma geral, constatou-se que, referente às áreas de atuação do PNAES, os participantes da pesquisa estão satisfeitos com as suas condições atuais, sendo as áreas inclusão digital, transporte e moradia as melhores avaliadas, e as áreas de saúde, creche e acessibilidade, as piores. Quanto ao grau de influência dessas áreas no alcance dos objetivos do programa, constatou-se que: na dimensão "desempenho acadêmico" as áreas que exercem maior influência são moradia, alimentação e inclusão digital; na dimensão "decisão de continuar no curso" as mais influentes são moradia, apoio pedagógico e alimentação; e na dimensão "concluir o curso dentro do prazo previsto" as áreas com maior influência são moradia, apoio pedagógico e inclusão digital. Quanto às áreas que apresentam menor influência nas três dimensões têm-se as áreas creche, esporte e cultura. Assim, para que o PNAES atinja os seus objetivos, as áreas mapeadas precisam ser constantemente monitoradas e avaliadas, de forma que a UFV possa adequar as ações de assistência realizadas às necessidades e espectativas dos seus beneficiários.

Palavras-chave: Ensino Superior. Programa Nacional de Assistência Estudantil. Avaliação de Políticas Públicas.

\begin{abstract}
This study aims to assess the National Program of Student Assistance (PNAES) at Universidade Federal de Viçosa (UFV) from the beneficiaries' point of view. For this, we conducted a descriptive and quantitative research, specifically a survey. The data were collected through questionnaires administered to a sample of 312 beneficiaries of the Program. To analyse data, we used descriptive statistics. In general, regarding the areas of PNAES, the findings show that research participants are satisfied with their current conditions. The areas of digital inclusion, housing and transport were assessed as the best ones and the areas of health, nursery and accessibility were assessed as the worst ones. We have also assessed the degree to which these areas influence the achievement of the objectives of the Program. The areas of housing, feeding and digital inclusion are the ones that have higher influence on the dimension "academic performance". The areas of housing, pedagogical support and feeding are the ones that have higher influence on the dimension "decision to continue the course". The areas of housing, pedagogical support and digital inclusion are the ones that have higher influence on the dimension "finish the course within the established time limit". The areas of nursery, sport and culture are the ones that have lower influence on the three dimensions above-mentioned. Thus, in order to achieve the objectives of PNAES, the mapped areas need to be constantly monitored and assessed so that UFV can tailor the assistance actions to meet the needs and expectations of its beneficiaries.
\end{abstract}

Keywords: Higher Education. National Program of Student Assistance. Assessment of Public Policies. 


\section{O PROGRAMA NACIONAL DE ASSISTÊNCIA ESTUDANTIL - PNAES NA UNIVERSIDADE FEDERAL DE VIÇOSA (UFV): UMA AVALIAÇÃO NA PERCEPÇÃO DOS BENEFICIÁRIOS \\ DOI: http://dx.doi.org/10.5007/1983-4535.2019v12n3p106}

\section{INTRODUÇÃO}

Nas últimas duas décadas, para democratizar o acesso à educação superior brasileira, o governo Federal criou várias políticas voltadas para a expansão da oferta de vagas, a construção de novas universidades públicas, a criação de cotas étnico-raciais e sociais e programas de permanência estudantil. Dentre elas, destaca-se o Programa Universidade para Todos (ProUni), o Programa de Financiamento Estudantil (Fies), o Programa de Apoio a Planos de Reestruturação e Expansão das Universidades Federais (Reuni), e as políticas de cotas (BARROS, 2010).

Dados do Instituto Nacional de Estudos e Pesquisas Educacionais - INEP, demonstram que o quantitativo de Instituições de Ensino Superior - IES saltou de 893 em 1991 para 2.416 em 2012, representando um crescimento de $171 \%$. O mesmo crescimento acelerado ocorreu com o número de matriculas, que passou de 1,5 milhões para mais de 7 milhões no período, representando um crescimento de cerca de $350 \%$ (RISTOFF, 2014).

Concomitantemente ao aumento das oportunidades de ingresso no nível superior, a permanência dos estudantes nas universidades tornou-se um tema de grande relevância, já que as políticas de democratização do acesso colaboraram para que alunos com condições socioeconômicas desfavoráveis e de distintas trajetórias educacionais fossem incluídas neste nível de ensino. Dados do Instituto Brasileiro de Geografia e Estatistica - IBGE demonstram que de 2004 a 2013 o acesso dos estudantes em situação de vulnerabilidade econômica e social saltou de 1,7\% para 7,2\% em universidades públicas (IBGE, 2014).

No entanto, tais políticas nem sempre trazem os resultados esperados, uma vez que não basta apenas garantir o acesso, há que se buscar também mecanismos que possam viabilizar a permanência e a conclusão no curso dos ingressantes no ensino superior. Neste contexto, com o objetivo de fornecer ações efetivas de permanência nas Instituições Federais de Ensino Superior - IFES, dando suporte às ações afirmativas de democratização do acesso ao ensino universitário e atendendo a uma demanda crescente dos dirigentes das IFES, através principalmente do Fórum Nacional dos Pró-reitores de Assistência aos Estudantes (FONAPRACE), o Governo Federal criou em 2007 o Programa Nacional de Assistência Estudantil (PNAES), a partir da Portaria Normativa $\mathrm{n}^{\mathrm{o}}$ 39, de 12 de dezembro de 2007, do Ministério da Educação (MEC). Em 2010, tal instrumento legal foi transformado no Decreto no 7.234/2010 (KOWALSKI, 2012).

O PNAES, em linhas gerais, busca possibilitar a permanência de alunos de baixa renda 


\section{O PROGRAMA NACIONAL DE ASSISTÊNCIA ESTUDANTIL - PNAES NA UNIVERSIDADE FEDERAL DE VIÇOSA (UFV): UMA AVALIAÇÃO NA PERCEPÇÃO DOS BENEFICIÁRIOS \\ DOI: http://dx.doi.org/10.5007/1983-4535.2019v12n3p106}

nos cursos de graduação, por meio da realização de atividades relacionadas às seguintes áreas: moradia, alimentação, transporte, assistência à saúde, inclusão digital, cultura, esporte, creche para filhos de alunos, apoio pedagógico, e acessibilidade. Tais atividades visam contribuir para o melhor desempenho acadêmico dos alunos atendidos e a redução da repetência e evasão (FONAPRACE et al., 2007).

Destaca-se que desde a criação do PNAES em 2008, observou-se um aumento de aproximadamente de $300 \%$ dos recursos financeitos destinados à assistência estudantil no país (WESKA et al., 2012). Em 2008 os recursos financeiros foram da ordem de 101 milhões e em 2016 foi de aproximadamente 1 bilhão. E esses valores vêm se tornando cada vez mais expressivos nos orçamentos das Universidades Federais, aumentando significativamente sua importância nas ações para o desenvolvimento do programa nas Universidades (MPOG/SIOP, 2018).

Diante do volume de recursos públicos destinados para o PNAES, e considerando a grande importância que as políticas educacionais para o ensino superior vêm ganhando na agenda pública brasileira, conjugado com o momento atual de uma maior pressão por parte da sociedade por mais eficiência no gasto dos recursos públicos, a avaliação destas e demais políticas sociais torna-se fundamental, tanto para melhorar a transparência governamental como para garantir melhores resultados nas políticas educacionais (CUNHA, 2006).

Por todo o exposto e considerando que o próprio Decreto de criação do PNAES (Decreto $\left.n^{\circ} 7.234 / 2010\right)$ estabelece, no seu artigo $5^{\circ}, \S$ único, inciso II, que as IFES deverão fixar mecanismos de acompanhamento e avalição desse programa, aponta-se para a necessidade de avaliá-lo, de modo a evidenciar o que deve ser feito e/ou corrigido para se alcançar os resultados esperados.

Neste contexto, pretende-se neste estudo responder à seguinte questão: Qual a percepção dos beneficiários do PNAES na Universidade Federal de Viçosa - UFV sobre as suas áreas de atuação? A escolha da UFV, localizada na região Zona da Mata de Minas Gerais, como unidade de análise deveu-se a determinadas características que corroboram para elucidação da questão de pesquisa, tais como a representatividade desta universidade no cenário nacional e especialmente no Estado, tendo em vista que A UFV é a segunda melhor Universidade de Minas Gerais e a $13^{\text {a }}$ do país de acordo com o Ranking Universitário da Folha (RUF) de 2017 (FOLHA DE SÃO PAULO, 2017), a manutenção de ações de assistência estudantil desde sua criação em 1926 (BORGES, 2010) e a facilidade de acesso 


\section{O PROGRAMA NACIONAL DE ASSISTÊNCIA ESTUDANTIL - PNAES NA UNIVERSIDADE FEDERAL DE VIÇOSA (UFV): UMA AVALIAÇÃO NA PERCEPÇÃO DOS BENEFICIÁRIOS \\ DOI: http://dx.doi.org/10.5007/1983-4535.2019v12n3p106}

aos dados a serem analisados, tendo em vista que os autores pertecem a essa instituição.

O objetivo geral do estudo consistiu em avaliar o PNAES na percepção de beneficiários, especialmente no que tange à satisfação destes quanto as suas condições atuais em áreas atendidas pelo programa e à influência dessas áreas no seu desempenho acadêmico, na conclusão do curso no tempo adequado e na evasão escolar, dimensões relacionadas aos objetivos que o programa busca alcançar.

Destaca-se que a importancia da avaliação pelo prisma dos beneficiários de políticas públicas é frequentemente eleita, pelos grandes estudiosos da avaliação, como Weiss (1998) e Patton (1997), como uma importante forma de melhorar a gestão dos poucos recursos públicos e aumentar o desempenho do programa, tendo em vista que se consegue formular intervenções mais adequadas às características do público-alvo.

\section{REFERENCIAL TEÓRICO}

O presente estudo tem como base teórica a literatura sobre Análise de Políticas Públicas, com foco na apresentação do conceito de políticas públicas e na explanação do modelo de análise denominado ciclo de políticas públicas ou "policy cycle", especialmente no que se refere à fase de avaliação de políticas públicas. Ademais, apresenta-se uma breve contextualização sobre o PNAES, objeto de estudo desse artigo.

\subsection{POLÍTICAS PÚBLICAS E CICLO POLÍTICO}

Obseva-se na literatura diversos entendimentos do que venha a ser políticas públicas. Tem-se adotado na ciência política o emprego dos conceitos em inglês de polity para denominar as instituições políticas, politics para os processos políticos e, por fim, policy para os conteúdos da política (FREY, 2000).

Souza (2006) define a política pública como a etapa na qual governos democráticos colocam em práticas seus propósitos e plataformas eleitorais, transformando-os em programas e ações que produzirão mudanças na realidade da sociedade. Rua (2012) define política pública como sendo soluções encontradas pela atividade política que envolve um conjunto de decisões e ações que alocam valores e atividades definidas estrategicamente para garantir a implementação da decisão tomada.

Modelos explicativos foram desenvolvidos para se compreender melhor como e por que o governo faz ou deixa de fazer determinada ação que implicará em alteração na realidade 
social das pessoas (SOUZA, 2006). Um desses modelos é o chamado Ciclo de Políticas (Policy Cycle), considerado uma tipologia que considera a política como um ciclo deliberativo, subdividido em fases (estágios) parciais do processo político-administrativo para a resolução de problemas da sociedade (FREY, 2000; SOUZA, 2006).

Embora o modelo sofra críticas por seu caráter funcionalista, que tenta manter o controle sobre os processos políticos, a adequada concepção do ciclo das políticas pode ser imprescindível para o gestor, favorecendo seu melhor entendimento do processo das políticas públicas e ajudando-o a refletir com clareza sobre como e mediante a que ferramentas as políticas poderão ser aprimoradas (RUA, 2012).

Para Frey (2000), as várias divisões do ciclo político sugeridas na literatura se diferenciam apenas gradualmente. De forma geral, as fases mais comuns apresentadas pelos autores são: definição da agenda, formulação, implementação e avaliação (FREY, 2000; SOUZA, 2006; RUA, 2012).

A definição da agenda diz respeito ao processo pelo qual os governos decidem quais questões precisam de sua atenção. Essa fase enfoca, entre outras coisas, a determinação e definição do que constitui o "problema", ou seja, que questões as políticas públicas subsequentes são destinadas a resolver (WU et al., 2014, p. 30). A fase de formulação "é o momento em que são elaborados métodos, programas, estratégias ou ações que poderão alcançar os objetivos estabelecidos (...) (SECCHI, 2014, p. 37).

A implementação compreende o conjunto dos eventos e atividades que acontecem após a definição das diretrizes de uma política, de tal maneira que as decisões tomadas deixem de ser apenas intenções para torna-se intervenções na realidade (RUA, 2012, p. 36). E a avaliação compreende os procedimentos de julgamento dos resultados de uma política que envolvem valores de forma sistemática, baseado em diretrizes reconhecidas e previamente estabelecidas dentro de uma política, programa ou projeto público, de forma a contribuir para a melhoria do processo decisório (RUA, 2012; BAMBERGER; TARSILLA; HESSE-BIBER, 2016).

\subsection{AVALIAÇÃO DE POLITICAS PUBLICAS}

A avaliação é frequentemente tema de debates entre os estudiosos da área de políticas públicas. Contudo, não há consenso sobre uma definição precisa do termo, embora um ponto em comum entre as definições seja a consideração de que o ato de avaliar significa determinar a 


\section{O PROGRAMA NACIONAL DE ASSISTÊNCIA ESTUDANTIL - PNAES NA UNIVERSIDADE FEDERAL DE VIÇOSA (UFV): UMA AVALIAÇÃO NA PERCEPÇÃO DOS BENEFICIÁRIOS \\ DOI: http://dx.doi.org/10.5007/1983-4535.2019v12n3p106}

valia de algo, atribuir um valor (SERAPIONI, 2016).

No campo das políticas públicas destaca-se uma perspectiva teórica convergente a três fatores importantes no processo avaliativo: a) foco nos procedimentos metodológicos de coleta dos dados que suportam o julgamento do mérito e valor das ações; b) avaliação como ferramenta imprescindível para melhoria da eficiência e qualidade da gestão dos programas e políticas pública, a partir do uso das suas informações para as tomadas de decisão gerenciais e estratégicas; e c) avaliação para formular juízo sobre o valor ou mérito de uma intervenção cujo objetivo é modificar a realidade social (SERAPIONI, 2016; BAMBERGER et al., 2006). De forma geral, pode-se compreender que a avaliação de políticas públicas se refere às atividades realizadas por um conjunto de atores estatais e sociais (stakeholders) com o fim de determinar o sucesso ou o fracasso de uma determinada política pública, bem como aferir o provável desempenho dela no futuro. A lista dos critérios que podem ser utilizados é longa e a escolha de um, ou vários deles, depende dos aspectos que se deseja privilegiar na avaliação (COSTA; CASTANHAR, 2005). Os critérios mais comuns apresentados no manual da Unicef (UNICEF, 2005) citado por Costa e Castanhar (2005) são: eficiência, eficácia, impacto (ou efetividade), sustentabilidade, análise custo-efetividade, satisfação do beneficiário e equidade.

Denota-se que, neste estudo, baseando-se nas classificações apresentadas pelos referidos autores, o estudo utiliza como um dos critérios para avaliar o PNAES a satisfação do beneficiário, o qual avalia a atitude do usuário em relação à qualidade do atendimento que está obtendo do programa (COSTA; CASTANHAR, 2005). A utilização desses critérios demanda formas específicas de operacionalização, já que constituem medidas indiretas, ou seja, que devem ser calculadas a partir da identificação e quantificação dos resultados obtidos. Desta forma, a mensuração dos resultados da avaliação requer a criação de indicadores, unidades que permitem medir o alcance de um objetivo específico (COSTA; CASTANHAR, 2005).

Outro aspecto importante que influencia a tipologia da avaliação de programas e políticas públicas diz respeito aos atores envolvidos no processo. Para Wu et al. (2014) a avaliação de políticas públicas refere-se amplamente a todas as atividades realizadas por uma gama de atores estatais e sociais com o intuito de determinar como uma política pública se saiu na prática, bem como estimar o provável desempenho dela no futuro. Corrobora com essa visão as obras de Patton (2013) que denomina os diferentes stakeholders (indivíduos, grupos ou organizações) que podem afetar ou serem afetados por um processo de avaliação e/ou seus 
resultados.

\subsection{O PROGRAMA NACIONAL DE ASSISTÊNCIA ESTUDANTIL - PNAES}

O PNAES surgiu em 2007, a partir da Portaria Normativa do Ministério da Educação $\mathrm{n}^{\mathrm{o}} 39$ de 12 de dezembro de 2007. De forma geral, o programa pode ser compreendido como um "braço" do REUNI (Programa de Apoio a Planos de Reestruturação e Expansão das Universidades Federais), programa que visava dotar as universidades federais das condições necessárias para ampliação do acesso e permanência na educação superior (BRASIL, 2007). Assim, o PNAES foi criado em resposta ao problema da falta de condições favoráveis à permanência no ensino superior de estudantes de baixa renda no contexto da grande expansão das instituições públicas federais e das políticas afirmativas que, em conjunto, trouxeram uma maior democratização no acesso ao ensino superior público de qualidade às camadas mais economicamente vulneráveis da sociedade brasileira (KOWALSKI, 2012).

Em 2010, frente à pressão social dos movimentos estudantis nas universidades públicas, dos dirigentes das IFES e do próprio programa REUNI, que previa a assistência aos estudantes de baixa renda, o Governo Federal instituiu o Decreto $n^{0} 7.234$ (KOWALSKI, 2012). Tal Decreto prevê como objetivos do PNAES em seu Art. $2^{\circ}$ :

I- democratizar as condições de permanência dos jovens na educação superior pública federal;

II - minimizar os efeitos das desigualdades sociais e regionais na permanência e conclusão da educação superior;

III- reduzir as taxas de retenção e evasão; e

IV - contribuir para a promoção da inclusão social pela educação (BRASIL, 2010).

Embora os objetivos estabelecidos no referido Decreto sejam bem claros, existem omissões quanto ao desenho da avaliação e monitoramento do programa, deixando a critério das IFES as metodologias e mecanismos de sua execução para o alcance dos objetivos.

No seu Art. $3^{\circ}$, o Decreto $n^{\circ} 7.234$ estabelece que a assistência estudantil deve ser articulada com atividades de ensino, pesquisa e extensão, com foco principal na permanência desses estudantes nos seus cursos de graduação. Além disso, no $\S 1^{\circ}$ do mesmo artigo, são definidas as áreas de atuação do PNAES, quais sejam: moradia estudantil; alimentação; transporte; assistência à saúde; inclusão digital; cultura; esporte; creche; apoio pedagógico; e 
acesso, participação e aprendizagem de estudantes com deficiência, transtornos globais do desenvolvimento e altas habilidades e superdotação (BRASIL, 2010).

Vale destacar que, embora o Decreto $\mathrm{n}^{0} 7.234$ defina as ações a serem implementadas no âmbito do programa, não define as formas de execução dessas ações, o que leva a uma diversidade de projetos e serviços implementados pelas IFES. Cita-se, por exemplo, a forma de implementação das ações de alimentação em que, algumas IFES, priorizam os investimentos em restaurantes universitários, com subvenções aos estudantes e, em outras, é fornecido o recurso monetário (IMPERATORI, 2017).

O Art. $5^{\circ}$ do Decreto $n^{\circ} 7.234$ estabelece a que público as ações de assistência devem atingir:

Art. $5^{\circ}$ serão atendidos no âmbito do PNAES prioritariamente estudantes oriundos da rede pública de educação básica ou com renda familiar per capita de até um salário mínimo e meio, sem prejuízo de demais requisitos fixados pelas instituições federais de ensino superior (BRASIL, 2010).

Diante do expoto, percebe-se que o PNAES não é uma política universal para todos os estudantes, há uma restrição no que se refere ao aspecto socioeconômico dos beneficiários. Além disso, o Decreto que o institui não menciona os mecanismos para o acesso ao programa, tampouco apresenta critérios para permanência dos estudantes como beneficiários do PNAES e nem a articulação do acesso com um dos objetivos do programa, expresso por meio do rendimento acadêmico (IMPERATORI, 2017).

\section{METODOLOGIA}

Este estudo caracteriza-se, quanto à sua natureza, como quantitativo, uma vez que busca-se quantificar os aspectos da realidade, tanto na coleta como no tratamento dos dados. Do ponto de vista de sua natureza, o estudo qualifica-se como aplicado, pois se espera que os seus resultados possam ser utilizados como referência para a avaliação e a resolução de problemas concretos de uma política pública - o PNAES, no contexto de uma universidade pública (MINAYO, 2001).

Com relação aos seus objetivos, o estudo caracteriza-se como descritivo, por envolver o uso de técnicas padronizadas de coleta de dados, questionários, em busca da descrição de um fenômeno. Quanto aos procedimentos adotados na coleta de dados, a pesquisa caracteriza-se como de levantamento, tendo em vista que houve a interrogação direta das pessoas sobre uma dada realidade. Neste tipo de estudo, solicita-se informações a 
um grupo significativo de pessoas acerca do problema estudado para, em seguida, mediante análise quantitativa, se obter as conclusões correspondentes aos dados coletados. Na maioria dos levantamentos, não são pesquisados todos os integrantes da população estudada (GIL, 2008).

O questionário utilizado na coleta de dados foi composto por questões que buscavam caracterizar o perfil dos estudantes beneficiários do PNAES, avaliar a percepção desses beneficiários sobre as suas condições atuais nas dez áreas de atuação do programa definidas no Decreto $\mathrm{n}^{\circ}$. 7.234/2010 (moradia estudantil; alimentação; transporte; atenção à saúde; inclusão digital; cultura; esporte; creche; apoio pedagógico; e acesso, participação e aprendizagem de estudantes com deficiência, transtornos globais do desenvolvimento e altas habilidades e superdotação) e, ainda identificar a percepção dos beneficiários sobre como as áreas de atuação do programa influenciam o "desempenho acadêmico", a "decisão de continuar no curso" (como indicador da evasão escolar) e as "condições de formatura dentro do prazo previsto para o curso" (como indicador de conclusão do curso), de forma a inferir sobre o alcance dos resultados esperados. Importante destacar que na elaboração do questionário, também levou-se em consideração contribuições de outros autores que também tiveram como objeto de estudo o PNAES (GIÚDICE, 2013; ANDRADE, 2014; PENHA, 2015).

Como critério de seleção dos participantes da pesquisa, priorizou-se os beneficiários que possuíam pelo menos o "produto" (auxílio estudantil) alimentação, tendo em vista que é permitido pelo programa graduandos terem apenas um tipo de benefício ou acumularem mais de um. Logo na amostra havia beneficiários que posuiam os sete produtos/serviços oferecidospela Pró-Reitoria de Assuntos Comunitários - PCD, relacionadas às dez áreas de atuação do PNAES, embora não haja ações específicas para todos, a exemplo da área de transporte, ou, pelo menos, o produto (alimentação).

A escolha deste filtro foi baseada em entrevistas realizadas junto a gestores que trabalham na área de assistência estudantil da UFV, ocorridas previamente à aplicação dos questionários, que apontaram a alimentação como uma das principais ações que possuem alta influência na permanência de estudantes em vulnerabilidade socioeconômica na UFV. Salienta-se que o conteúdo dessas entrevistas, que extrapolaram a constatação mencionada, não constituiu fonte de dados para a análise deste artigo. Ademais, considerando que o número de beneficiários atendidos simultaneamente por todos os produtos/serviços 
oferecidos pela PCD poderia diminuir significativamente o número de participantes da pesquisa e ainda, que o estudo busca avaliar a percepção dos beneficiários sobre as suas condições atuais nas áreas de atuação do PNAES, considerou-se que todos teriam condição de avaliá-lo, mesmo que não diretamente beneficiário em alguma de suas áreas.

Para a identificação dos beneficiários, inicialmente foi solicitado (e autorizado) à Pró Reitoria de Assuntos Comunitários (PCD), um relatório contendo os endereços de $e$ mail dos estudantes que atendiam ao critério apresentado acima. Tal relatório foi gerado através do Sistema Informatizado de Gestão de Bolsas (SISBOLSA) em 16 de abril de 2018. Também a partir do SISBOLSA, foram enviados os e-mails aos beneficiários contendo uma breve descrição da pesquisa e um link que direcionava o participante para a plataforma do Google docs onde se encontrava o questionário a ser respondido.

Ao todo, foram enviados questionários para 1.487 beneficiários (população definida a partir do critério de seleção adotado), ficando no status de "recebendo respostas" do dia 17/04/2018 ao dia 13/06/2018. Após esse período foram obtidas 312 respostas. Importante mencionar que este número de participantes pode ser considerado uma amostra significativa, tendo em vista os cálculos realizados segundo a fórmula finita apresentada por Gil (2008), onde: $\mathrm{n}=$ amostra calculada; $\mathrm{N}=$ população; $\mathrm{Z}=$ variável normal padronizada associada ao nível de confiança; $\mathrm{p}=$ é a percentagem com a qual o fenômeno severifica; e e = erro amostral (GIL, 2008; Santos [s.d.]).

$$
n=\frac{N \cdot Z^{2} \cdot p \cdot(1-p)}{Z^{2} \cdot p \cdot(1-p)+e^{2} \cdot(N-1)}
$$

Para proceder ao cálculo com o auxílio da fórmula, adotou-se, $\mathrm{N}=1487$ (tamanho da população de beneficiários que recebem pelo menos a alimentação), para a definição da amostra, o erro de $5 \%(\mathrm{e}=5)$ e $95 \%$ de confiança $(Z=1,96)$, baeando-se em Bolfarine e Bussab (2005). Como regra geral, usou-se $p=50 \%$ por não se ter nenhuma informação sobre o valor que se espera encontrar. Desta forma substituindo-se os valores na fórmula apresenta acima, obte-ve o valor de 306 beneficiários. Logo as 312 respostas obtidas estão dentro do quantitativo esperado.

Os dados foram analisados por meio do método de Estatística Descritiva, com o suporte do programa estatístico Statistical Package for the Social Sciences (SPSS). Segundo Ferreira (2005), a estatística descritiva tem como objetivo a descrição dos dados, sejam eles de uma amostra ou de uma população, e pode incluir compilação de dados em tabela, elaboração de gráficos e cálculos de valores de sumários, tais como médias, desvio-padrão, 
variância e outros.

\section{RESULTADOS E DISCUSSÃO}

\subsection{CARACTERIZAÇÃO DOS RESPONDENTES}

Do total de participantes da pesquisa (312), constatou-se que 57,1\% eram do sexo feminino e $42,9 \%$ do sexo masculino, sendo a maioria solteira $(95,2 \%)$. Em relação a faixa etária, a média de idade dos beneficiários é de 22 anos, resultado muito semelhante à IV Pesquisa do perfil socioeconômico e cultural dos estudantes de graduação das IFES elaborado em 2014 pela ANDIFES/FONAPRACE.

No tocante à origem escolar, constatou-se que mais de $90 \%$ dos beneficiários são oriundos da rede de ensino público (Tabela 1).

Tabela 1 Origem escolar dos beneficiários

\begin{tabular}{lcllc}
\hline \multicolumn{1}{c}{ Realizou o ensino fundamental em: } & $\mathbf{\%}$ & Realizou o ensino médio em: & $\%$ \\
\hline Escola particular - sem bolsa & $3 \%$ & Escola particular - sem bolsa & $2 \%$ \\
Escola particular - bolsa integral & $3 \%$ & Escola particular - bolsa integral & $4 \%$ \\
Escola particular - bolsa parcial & $1 \%$ & Escola particular - bolsa parcial & $2 \%$ \\
Escola pública & $94 \%$ & Escola pública & $92 \%$ \\
\hline Total respondentes & $\mathbf{1 0 0 \%}$ & Total respondentes & $\mathbf{1 0 0 \%}$ \\
\hline
\end{tabular}

Fonte: Resultado da pesquisa.

Assim, observa-se que o critério de elegibilidade do público-alvo, ou seja, que “serão atendidos no âmbito do PNAES prioritariamente estudantes oriundos da rede pública de educação básica", conforme prescrito no art. $5^{\circ}$ do Decreto $\mathrm{n}^{\circ} .7 .234 / 2010$, está sendo atendido (BRASIL, 2010).

Quando questionado aos beneficiários se o auxilio recebido pela assistência estudantil é suficiente para a manutenção dos estudos, $76 \%$ responderam que não é suficiente e 74\% afirmara que recebem ajuda financeira dos pais ou responsáveis. Sobre o custo médio mensal para a manutenção dos estudos na UFV, a maioria (61\%) dos respondentes precisariam de um benefício maior que $\mathrm{R} \$ 360,00$.

No tocante à área de conhecimento dos respondentes, verificou-se representação de todos os Centros: Centro de Ciências Humanas $(\mathrm{CCH})$ com 31\%, Centro de Ciências Exatas (CCE) com 28\%, Centro de Ciências Agrárias (CCA) com 24\%, e o Centro de Ciências 
Biológicas (CCB) com 17\%. Desta forma, percebe-se que há uma amplitude da assistência estudantil em todas as áreas de conhecimento da Universidade, sobretudo nas áreas de ciências humanas. Denota-se, porém, que $25 \%$ dos beneficiários indicaram já terem mudado de curso após ingressarem na UFV.

Figura 1 Custo médio mensal apontado pelos beneficiários.

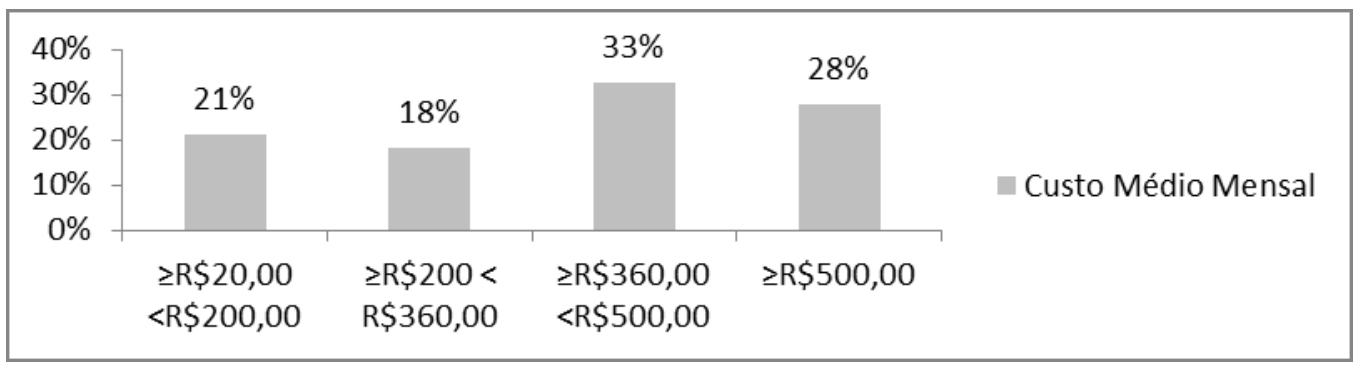

Fonte: Resultado da pesquisa

No que diz respeito o ano de ingresso e previsão de conclusão do curso a Tabela 2 demonstra a proporção de beneficiários segundo o ano de ingresso e o ano provável de conclusão do curso de graduação.

Quadro 1 Ano de ingresso na UFV e previsão de conclusão do curso.

\begin{tabular}{|c|c|c|c|c|c|c|c|}
\hline & \multicolumn{7}{|c|}{ Ano de previsão de conclusão do curso } \\
\hline Ano de Ingresso na UFV & $\mathbf{2 0 1 8}$ & $\mathbf{2 0 1 9}$ & $\mathbf{2 0 2 0}$ & $\mathbf{2 0 2 1}$ & $\mathbf{2 0 2 2}$ & $\mathbf{2 0 2 3}$ & $\begin{array}{c}\text { Total de } \\
\text { Ingressantes por ano }\end{array}$ \\
\hline 2005 & & & & & 1 & & $\mathbf{1}$ \\
\hline 2010 & 1 & & & & & & $\mathbf{1}$ \\
\hline 2011 & 3 & 3 & 2 & 1 & & & $\mathbf{9}$ \\
\hline 2012 & 2 & 5 & & & & & $\mathbf{2 4}$ \\
\hline 2013 & 11 & 7 & 5 & 1 & & & $\mathbf{2 8}$ \\
\hline 2014 & 5 & 18 & 3 & 2 & & & $\mathbf{6 2}$ \\
\hline 2015 & 8 & 17 & 28 & 6 & 1 & 1 & $\mathbf{6 8}$ \\
\hline 2016 & & 13 & 22 & 21 & 6 & & $\mathbf{4 4}$ \\
\hline 2017 & & 1 & 13 & 33 & 20 & 1 & $\mathbf{3 0 5}$ \\
\hline $\begin{array}{c}\text { Total de Previsão de } \\
\text { Conclusão por ano }\end{array}$ & $\mathbf{3 0}$ & $\mathbf{6 4}$ & $\mathbf{7 5}$ & $\mathbf{6 8}$ & $\mathbf{5 5}$ & $\mathbf{1 3}$ & 11 \\
\hline
\end{tabular}

*Amostra: 312; Respostas invalidadas: 7; respostas válidas: 305

Fonte: resultados da pesquisa.

Observa-se, conforme Quadro 1, uma pequena frequência de beneficiários ingressantes nos anos de 2005 a 2012. Considerando que a média de tempo para concluir um curso com duração entre quatro e sete anos conforme as matrizes curriculares constantes no catálogo de graduação da UFV estão em torno de quatro anos, os ingressantes do período entre 2005 a 2012 estão fora do prazo médio de duração do curso. Uma possível justificativa 


\section{O PROGRAMA NACIONAL DE ASSISTÊNCIA ESTUDANTIL - PNAES NA UNIVERSIDADE FEDERAL DE VIÇOSA (UFV): UMA AVALIAÇÃO NA PERCEPÇÃO DOS BENEFICIÁRIOS \\ DOI: http://dx.doi.org/10.5007/1983-4535.2019v12n3p106}

para esse fato é que, dos dezoito estudantes respondentes e ingressantes neste período, 39\% haviam mudado de curso no período.

No que se refere ao grau de instrução dos pais dos beneficiários, o ensino fundamental incompleto predominou na maioria das respostas, sendo que $51 \%$ das mães e $44 \%$ dos pais possuem esse grau de instrução. Observa-se que o ensino médio completo aparece na segunda colocação, com $29 \%$ das mães e $22 \%$ dos pais. Frisa-se que apenas $7 \%$ das mães e $5 \%$ dos pais possuem grau de instrução maior que dos beneficiários. Portanto pode-se afirmar que a maioria dos beneficiários possuem mães e pais com escolaridade inferior à deles.

No tocante à renda mensal bruta do grupo familiar, constatou-se que $74,68 \%$ dos beneficiários tem renda mensal bruta de até um salário mínimo vigente, ou seja, R\$954,00, seguido pela faixa salarial de 1 a 3 salários mínimos (até $\mathrm{R} \$ 2.862,00$ ) com percentual de $21,79 \%$. Ao realizar a referência cruzada entre a renda mensal bruta informada e o número de dependentes desta renda, obteve-se os dados da Tabela 2, levando-se em consideração a exclusão de 22 respostas inválidas.

Tabela 2 Renda bruta mensal e número de pessoas dependente dessa renda.

\begin{tabular}{|c|c|c|c|c|c|c|c|c|c|c|}
\hline \multirow{3}{*}{$\begin{array}{c}\text { Número de } \\
\text { pessoas } \\
\text { dependente } \\
\text { da renda } \\
\text { familiar } \\
1\end{array}$} & \multicolumn{8}{|c|}{ Renda bruta mensal } & & \\
\hline & \multicolumn{2}{|c|}{$\begin{array}{c}\text { Até um } \\
\text { salário } \\
\text { mínimo (até } \\
954 \text { reais) }\end{array}$} & \multicolumn{2}{|c|}{$\begin{array}{c}\text { De } 1 \text { a } 3 \\
\text { salários } \\
\text { mínimos (até } \\
2.862 \text { reais) }\end{array}$} & \multicolumn{2}{|c|}{$\begin{array}{c}\text { De } 3 \text { a } 5 \\
\text { salários } \\
\text { mínimos (até } \\
4.770 \text { reais) }\end{array}$} & \multicolumn{2}{|c|}{$\begin{array}{c}\text { De } 5 \text { a } 10 \\
\text { salários } \\
\text { mínimos } \\
\text { (até } 9.540 \\
\text { reais) }\end{array}$} & \multicolumn{2}{|c|}{ Total* } \\
\hline & 9 & $3 \%$ & 1 & $0 \%$ & 0 & $0 \%$ & 0 & $0 \%$ & 10 & $3 \%$ \\
\hline 2 & 25 & $9 \%$ & 6 & $2 \%$ & 0 & $0 \%$ & 0 & $0 \%$ & 31 & $11 \%$ \\
\hline 3 & 65 & $22 \%$ & 13 & $4 \%$ & 2 & $1 \%$ & 0 & $0 \%$ & 80 & $28 \%$ \\
\hline 4 & 72 & $25 \%$ & 26 & $9 \%$ & 1 & $0 \%$ & 0 & $0 \%$ & 99 & $34 \%$ \\
\hline 5 & 38 & $13 \%$ & 13 & $4 \%$ & 3 & $1 \%$ & 1 & $0 \%$ & 55 & $19 \%$ \\
\hline 6 & 9 & $3 \%$ & 2 & $1 \%$ & 0 & $0 \%$ & 0 & $0 \%$ & 11 & $4 \%$ \\
\hline 7 & 3 & $1 \%$ & 1 & $0 \%$ & 0 & $0 \%$ & 0 & $0 \%$ & 4 & $1 \%$ \\
\hline Total & 221 & $76 \%$ & 62 & $21 \%$ & 6 & $2 \%$ & 1 & $0 \%$ & 290 & $100 \%$ \\
\hline
\end{tabular}

*Referência cruzada: respondentes: 312, respostas invalidas: 22, valores válidos: 290 Fonte: Resultado da pesquisa.

Destaca-se que a média de dependentes da renda familiar foi de quatro integrantes, correspondendo ao percentual de $34 \%$ dos entrevistados. Somando-se os grupos familiares com três a cinco dependentes obtém-se $81 \%$ dos beneficiários. Dentro desse grupo $60 \%$ recebem até $\mathrm{R} \$ 954,00$ brutos, uma média per capita de $\mathrm{R} \$ 238,50$. Conforme Faria, Feijó e 


\section{O PROGRAMA NACIONAL DE ASSISTÊNCIA ESTUDANTIL - PNAES NA UNIVERSIDADE FEDERAL DE VIÇOSA (UFV): UMA AVALIAÇÃO NA PERCEPÇÃO DOS BENEFICIÁRIOS \\ DOI: http://dx.doi.org/10.5007/1983-4535.2019v12n3p106}

Silva (2007) revelam, considera-se pobre o indivíduo que possui renda familiar per capita de $1 / 2$ do salário mínimo vigente $(\mathrm{R} \$ 477,00)$ e indigente, abaixo da linha da pobreza, aquele que possua renda per capital de $1 / 4$ do salário mínimo vigente $(\mathrm{R} \$ 238,50)$. Desta forma, constatase que pelo menos $60 \%$ dos respondentes da pesquisa, considerando os dependentes da renda bruta mensal, enquadram-se em situação extrema de pobreza, confirmando o grande desafio que a assistência estudantil tem que enfrentar no cenário atual das IFES.

\subsection{AVALIAÇÃO DA SATISFAÇÃO DOS RESPONDENTES COM RELAÇÃO ÀS SUAS CONDIÇÕES ATUAIS NAS ÁREAS DE ATUAÇÃO DO PNAES}

Para identificar a percepção dos beneficiários em relação às suas condições atuais em cada uma das áreas definidas pelo PNAES e avaliar se eles enxergam que há relação dessas áreas com os resultados finais pretendidos pelo programa (coeficiente de rendimento, taxa de retenção e evasão e taxa de concluintes), considerou-se pertinente conhecer, primeiramente, como as dez áreas de atuação do programa se apresenta no cotidiano dos beneficiários.

Ao analisar a área de transporte, é pertinente demonstrar a cidade de origem dos entrevistados. Dados da pesquisa revelaram que 79\% dos beneficiários são de cidades que estão distantes do Campus de Viçosa e, por isso, estão mais inclinados a morarem no entorno do Campus, ou em alojamento, otimizando seu tempo de deslocamento para as atividades acadêmicas. Do total de respondentes, 40,97\% moram nos alojamentos do Campus Viçosa e $38,71 \%$ moram no seu entorno. Ademais, constatou-se que apenas $10,06 \%$ dos respondentes poderiam ser potenciais demandantes de auxílio transporte, por utilizarem meio de transporte público intermunicipal, subsidiado, locado ou carona. Desta forma, os dados encontrados corroboram para o fato de não existirem ações da UFV em relação a área de transporte.

Com relação à alimentação, constatou-se que 94,23\% dos respondentes, geralmente, fazem as principais refeições nos restaurantes universitários ou no restaurante multiuso no campus de Viçosa, tendo como principal motivo para essa opção o recebimento de auxílio alimentação (Tabela 3).

Os dados apresentados na Tabela 3 corroboram para evidenciar que, embora todos os respondentes da pesquisa sejam beneficiários do auxílio alimentação, 1,28\% não o utiliza pelo motivo de estarem em trabalho/estágios e a localização e o tempo disponível favorecer a alimentação perto do local onde estejam. E 0,64\% fazem suas refeições em casa devido à localização/distância e ao sabor e qualidade da comida. 


\section{O PROGRAMA NACIONAL DE ASSISTÊNCIA ESTUDANTIL - PNAES NA UNIVERSIDADE FEDERAL DE VIÇOSA (UFV): UMA AVALIAÇÃO NA PERCEPÇÃO DOS BENEFICIÁRIOS \\ DOI: http://dx.doi.org/10.5007/1983-4535.2019v12n3p106}

Tabela 3 Caracterização da área de alimentação entre os beneficiários.

\begin{tabular}{|c|c|c|c|c|c|c|c|c|c|c|c|c|}
\hline \multirow{3}{*}{$\begin{array}{c}\text { Onde você, geralmente, } \\
\text { costuma fazer suas } \\
\text { principais refeições (café da } \\
\text { manhã, almoço, jantar) }\end{array}$} & \multicolumn{10}{|c|}{ Qual o principal motivo para sua opção } & \multirow{2}{*}{\multicolumn{2}{|c|}{ Total }} \\
\hline & \multicolumn{2}{|c|}{$\begin{array}{c}\text { Auxílio } \\
\text { alimentação }\end{array}$} & \multicolumn{2}{|c|}{$\begin{array}{l}\text { Custo da } \\
\text { refeição }\end{array}$} & \multicolumn{2}{|c|}{$\begin{array}{c}\text { Localização/dis } \\
\text { tância }\end{array}$} & \multicolumn{2}{|c|}{$\begin{array}{c}\text { Sabor/qualidade } \\
\text { da comida }\end{array}$} & \multicolumn{2}{|c|}{$\begin{array}{c}\text { Tempo } \\
\text { disponível }\end{array}$} & & \\
\hline & Freq. & $\%$ & Freq. & $\%$ & Freq. & $\%$ & Freq. & $\%$ & Freq. & $\%$ & Freq. & $\%$ \\
\hline $\begin{array}{l}\text { Na minha casa ou casa de } \\
\text { amigos/parentes }\end{array}$ & 0 & $0,00 \%$ & 0 & $0,00 \%$ & 1 & $0,32 \%$ & 1 & $0,32 \%$ & 0 & $0,00 \%$ & 2 & $0,64 \%$ \\
\hline $\begin{array}{l}\text { No trabalho/estágio ou em } \\
\text { algum local próximo }\end{array}$ & 1 & $0,32 \%$ & 0 & $0,00 \%$ & 2 & $0,64 \%$ & 0 & $0,00 \%$ & 1 & $0,32 \%$ & 4 & $1,28 \%$ \\
\hline R.U ou Multiuso & 294 & $94,23 \%$ & 7 & $2,24 \%$ & 2 & $0,64 \%$ & 0 & $0,00 \%$ & 3 & $0,96 \%$ & 306 & $98,08 \%$ \\
\hline TOTAL & 295 & $94,55 \%$ & 7 & $2,24 \%$ & 5 & $1,60 \%$ & 1 & $0,32 \%$ & 4 & $1,28 \%$ & 312 & $100,00 \%$ \\
\hline
\end{tabular}

Fonte: Resultado da pesquisa.

Com relação à moradia, 45,19\% dos beneficiários participantes da pesquisa moram em alojamentos e 13,78\% possuem auxílio moradia na cidade de Viçosa. Assistidos pelas atividades do PNAES, mas que não recebem assistência na área de moradia somam o percentual de 41,03\%. Esse percentual refere-se às situações de moradia como imóvel alugado, na casa de pais ou parentes, de favor com amigos/parentes/conhecidos e outras situações (Tabela 4).

Pela análise da Tabela 4, verifica-se que dos 135 estudantes que moram na cidade com auxilio moradia ou imóvel alugado, $113(36,22 \%)$ indicaram ter um espaço reservado para seus estudos ou um quarto individual. Diferentemente dos moradores de alojamento, em que apenas $44(14,10 \%)$ dos 141 que indicaram morar nos alojamentos, informaram ter um espaço reservado para os estudos.

Tabela 4 Caracterização da área de moradia entre os beneficiários.

\begin{tabular}{|c|c|c|c|c|c|c|}
\hline \multirow{3}{*}{ Onde você mora atualmente? } & \multicolumn{4}{|c|}{$\begin{array}{l}\text { Em sua residência atual, você tem } \\
\text { um espaço reservado para seus } \\
\text { estudos ou um quarto individual? }\end{array}$} & \multirow{2}{*}{\multicolumn{2}{|c|}{ Total }} \\
\hline & \multicolumn{2}{|c|}{ Não } & \multicolumn{2}{|c|}{ Sim } & & \\
\hline & Freq. & $\%$ & Freq. & $\%$ & Freq. & $\%$ \\
\hline Alojamento no Campus UFV & 97 & $31,09 \%$ & 44 & $14,10 \%$ & 141 & $45,19 \%$ \\
\hline $\mathrm{Na}$ cidade, imóvel alugado & 16 & $5,13 \%$ & 76 & $24,36 \%$ & 92 & $29,49 \%$ \\
\hline Na cidade com auxílio moradia & 6 & $1,92 \%$ & 37 & $11,86 \%$ & 43 & $13,78 \%$ \\
\hline Na casa dos meus pais ou parentes & 6 & $1,92 \%$ & 12 & $3,85 \%$ & 18 & $5,77 \%$ \\
\hline Outra situação & 6 & $1,92 \%$ & 6 & $1,92 \%$ & 12 & $3,85 \%$ \\
\hline $\begin{array}{l}\text { De favor com } \\
\text { amigos/parentes/conhecidos }\end{array}$ & 5 & $1,60 \%$ & 1 & $0,32 \%$ & 6 & $1,92 \%$ \\
\hline TOTAL & 136 & $43,59 \%$ & 176 & $56,41 \%$ & 312 & $100,00 \%$ \\
\hline
\end{tabular}

Fonte: Resultado da pesquisa. 


\section{O PROGRAMA NACIONAL DE ASSISTÊNCIA ESTUDANTIL - PNAES NA UNIVERSIDADE FEDERAL DE VIÇOSA (UFV): UMA AVALIAÇÃO NA PERCEPÇÃO DOS BENEFICIÁRIOS \\ DOI: http://dx.doi.org/10.5007/1983-4535.2019v12n3p106}

Com relação à área de inclusão digital, foi perguntando aos beneficiários quais equipamentos eletrônicos de informática eles possuíam e se tinham acesso à internet. Constatou-se que 97,75\% possuem algum tipo de equipamento eletrônico entre computador, smartphone ou tablet e apenas 2,25\% não possuem nenhum desses tipos de eletrônicos. A grande maioria possui acesso à internet $(95,18 \%)$ e mesmo aqueles que não possuem equipamentos eletrônicos indicaram que possuem acesso à internet em sua residência.

Com relação às áreas de saúde, cultura, esporte e lazer, a pesquisa revelou que $63,46 \%$ dos beneficiários recorrem à divisão de saúde quando necessitam de atendimento médico ou psicológico, 26,92\% utilizam os hospitais públicos no município de Viçosa. Outra forma de resolver o problema foi indicado em 4,17\%, tais como aguardar até que o problema de saúde se resolva com o passar do tempo e ir para a cidade de origem resolver o problema perto da família. Dos beneficiários pesquisados apenas 27,56\% utilizam ou já utilizaram os serviços da Divisão Psicossocial, 24,36\% participam de alguma atividade de esporte e lazer e 22,44\% realizam atividades culturais promovidas pela UFV.

Sob a ótica dos beneficiários, o ranking do grau de satisfação nas diferentes áreas de atuação do PNAES é apresentado no Quadro 2 e no Quadro 3 apresenta-se o ranking do grau de influência das atividades do PNAES nos principais indicadores de resultado final.

Quadro 2 Ranking das médias de satisfação das diferentes áreas do PNAES.

\begin{tabular}{|c|c|c|}
\hline Ranking de satisfação nas diferentes áreas do PNAES, segundo os beneficiários \\
\hline Áreas do PNAES & \multicolumn{2}{|c|}{ Média em Ranking } \\
\hline Inclusão digital & $1^{\mathbf{0}}$ & 3,590 \\
\hline Transporte & $2^{\mathbf{o}}$ & 3,516 \\
\hline Moradia & $3^{\mathbf{0}}$ & 3,368 \\
\hline Alimentação & $4^{\mathbf{0}}$ & 3,288 \\
\hline Apoio pedagógico & $5^{\mathbf{0}}$ & 3,193 \\
\hline Esporte e lazer & $6^{\mathbf{0}}$ & 3,055 \\
\hline Cultura & $7^{\mathbf{0}}$ & 2,948 \\
\hline Saúde & $8^{\mathbf{0}}$ & 2,759 \\
\hline Creche & $9^{\mathbf{0}}$ & 2,678 \\
\hline Acessibilidade & $10^{\mathbf{o}}$ & 2,574 \\
\hline
\end{tabular}

Fonte: Resultado da pesquisa

Nota $\left({ }^{1}\right)$ : Dados obtidos da aplicação de questionários com escala do tipo Likert de 05 pontos, sendo 01(nada satisfeito) a pontuação mínima e 05 (plenamente satisfeito) corresponde a pontuação máxima. 


\section{O PROGRAMA NACIONAL DE ASSISTÊNCIA ESTUDANTIL - PNAES NA UNIVERSIDADE FEDERAL DE VIÇOSA (UFV): UMA AVALIAÇÃO NA PERCEPÇÃO DOS BENEFICIÁRIOS \\ DOI: http://dx.doi.org/10.5007/1983-4535.2019v12n3p106}

Quadro 3 Grau de influência das atividades do PNAES nos principais objetivos do programa.

\begin{tabular}{|l|c|c|c|c|c|c|}
\hline \multicolumn{7}{|c|}{ Ranking do Grau de influência das atividades do PNAES nos principais indicadores de } \\
resultado final
\end{tabular}

Fonte: Resultado da pesquisa

Nota $\left({ }^{2}\right)$ : Dados obtidos da aplicação de questionários com escala do tipo Likert de 05 pontos, sendo 01(não influência) a pontuação mínima e 05 (influência totalmente) corresponde a pontuação máxima.

Conforme Quadro 3, observa-se que as cinco áreas que exercem maior influência na dimensão "Decisão de continuar o curso" foram: moradia, apoio pedagógico, alimentação, inclusão digital, saúde; na dimensão "Concluir o curso dentro do prazo previsto" foram: moradia, apoio pedagógico, inclusão digital, saúde e alimentação. E na dimensão "Desempenho acadêmico" as áreas que apresentaram maior influência foram: moradia, alimentação, inclusão digital, saúde e apoio pedagógico.

Ressalta-se que a área de saúde está entre as cinco áreas que exercem maior influência nos principais objetivos do programa, no entanto, teve média de satisfação entre os beneficiários de 2,759, acima apenas da área de creche e acessibilidade. Infere-se desses dados que a área de saúde não está atendendo satisfatoriamente os beneficiários, embora os entrevistados tenham declarado ser uma área que influencia totalmente seu coeficiente de rendimento, com média de 4,02, a decisão de continuar no curso, com média de 3,43, e de concluir o curso o tempo adequado, com média de 3,68, destacando a maior influência desta área no desempenho acadêmico.

As áreas que receberam menores médias de satisfação foram cultura $(2,948)$, saúde $(2,759)$, creche $(2,678)$ e acessibilidade $(2,574)$. Interessante notar que a área do transporte obteve média alta na satisfação entre os beneficiários $(3,516)$, mas média baixa no grau de influência nos principais indicadores de resultado final do programa, ocupando o oitavo e nono lugar apenas. Esse fato pode ser explicado pelas características da área de transporte dos 
estudantes no Campus Viçosa. As observações dos dados da pesquisa em relação a área de transporte auferiram que dos entrevistados $86,69 \%$ declararam se deslocar a pé ou de bicicleta de sua residência até a UFV, e, apenas $10,06 \%$, poderiam ser potenciais demandantes de auxílio transporte por utilizarem meio de transporte público intermunicipal, subsidiado, locado ou carona.

Outro caso a ser destacado é a área de esporte e cultura em relação ao grau de influência e grau de satisfação. Destaca-se o fato de que os beneficiários terem indicado que essas áreas possuem pouca influência nos indicadores de resultado final, ocupando as últimas colocações (sétimo, oitavo e nono lugar), bem como apresentar médias baixas no grau de satisfação.

Compreende-se desses dados, comparados com o baixo grau de satisfação da área de cultura $(2,948)$ e à média de satisfação na área de esporte $(3,055)$, que haveria espaço para adequar melhor as atividades dessa área de atuação do PNAES de acordo com as demandas dos beneficiários, de tal forma que colaborasse melhor para desenvolver benefícios que se correlacionam com o sucesso acadêmico do estudante.

Silva e Ehrenberg (2017) ressaltam a importância de se estabelecer políticas públicas que garantam condições mínimas para a promoção de capital cultural pelas famílias mais pobres como meio de redução e combate da desigualdade social e desenvolvimento do país. Essa fala corrobora com o entendimento que, melhorar a qualidade das atividades culturais poderá beneficiar o sucesso acadêmico dos assistidos pela política do PNAES na UFV.

No que se refere ao auxílio creche, constatou-se baixo grau de influência nas dimensões que refletem os objetivos do programa, tendo em vistas as baixas médias em todas elas. O grau de satisfação também foi baixo (média de 2,678). Denota-se que esse é um auxílio muito específico e flutuante. Em 2016, por exemplo, apenas 17 estudantes possuíam esse benefício. Dados da presente pesquisa revelaram que apenas cinco participantes tinham filhos com até 5 anos de idade e que, portanto, teriam direito ao auxílio creche. Dentre eles, o grau de satisfação foi em média 2 (pouco satisfeito) e o grau de influência foi de pouca influência no desempenho acadêmico, não influenciando na decisão de continuar no curso nem na intenção de conclui-lo dentro do prazo previsto. Tais resultados vão ao encontro das conclusões do estudo de Andrade (2014), que não encontrou diferenças estatisticamente significativas no desempenho acadêmico entre os estudantes que têm filhos e os que não têm, tampouco considerando somente os que têm filhos pequenos de até 5 anos de idade. 
O Decreto $n^{0}$. 7.234/2010 estabelece como um dos seus objetivos a redução da taxa de retenção e evasão. O aumento dessas taxas reflete alguns dos problemas que mais incomodam as instituições de ensino em geral, pois afetam os resultados dos sistemas educacionais, aumentam o custo aluno e atrapalha o mercado de trabalho, por não dispor de mão de obra qualificada dentro do time esperado pela economia do país.

No entanto, é importante destacar que as causas da retenção e evasão tem raízes em vários aspectos, não se limitando às áreas de atuação do PNAES. Para Baggi e Lopes (2011) o tema envolve questões pedagógicas, psicológicas, sociais, políticas, econômicas, administrativas, dentre outras, no entanto, muitas pesquisas na área vêm apontando como principal razão da retenção e evasão a falta de recursos financeiros para o aluno prosseguir seus estudos.

Na pesquisa em questão, a ideia foi verificar quais áreas de atuação do PNAES, além de contribuir para o desempenho acadêmico dos beneficiários do programa, tem maior influência na decisão destes de continuar no curso e de conclui-lo dentro do prazo previsto na matriz curricular, sem, contudo, deixar de considerar que outros fatores também podem afetar tais aspectos.

\section{CONCLUSÕES}

A importância da avaliação pelo prisma dos beneficiários de políticas públicas é frequentemente eleita, pelos grandes estudiosos da avaliação, como uma importante forma de melhorar a gestão dos poucos recursos públicos e aumentar o desempenho do programa, tendo em vista que se consegue formular intervenções mais adequadas às características do públicoalvo.

A análise de estatística descritiva e referências cruzadas mostraram-se apropriadas para revelar a percepção dos beneficiarios sobre as suas atuais condições em relação às áreas de atuação do PNAES, no Campus de Viçosa. Permitindo inferir que, de modo geral os estudantes estão satisfeitos com as suas condições atuais em relação às essas áreas. Em média, constatou-se que as áreas de inclusão digital, transporte e moradia são as que os estudantes estão mais satisfeitos. E as áreas de menor satisfação foram saúde, creche e acessibilidade.

No que se refere à percepção dos beneficiários sobre o grau de influência dessas áreas nos principais objetivos do PNAES, a pesquisa revelou que na dimensão "Desempenho acadêmico" as áreas mais influentes foram: moradia, alimentação, inclusão digital, saúde e 
apoio pedagógico. $\mathrm{Na}$ dimensão "Decisão de continuar no curso" foram: moradia, apoio pedagógico, alimentação, inclusão digital e saúde e na dimensão "Concluir o curso dentro do prazo previsto" as áreas mais influentes foram: moradia, apoio pedagógico, inclusão digital, saúde e alimentação. Logo, para que o programa atinja maior alcance, as áreas que obtiveram maior grau de influência nas referidas dimensões precisam ser constantemente monitoradas e avaliadas para que as ações de assistência realizadas pela UFV sejam adequadas às necessidades e espectativas dos beneficiários.

Pontua-se que a contribuição deste estudo está, principalmente, em dotar os gestores de informações efetivas sobre o PNAES, de forma a responder aos controles internos e externos com maior precisão nos seus diversos questionamentos e a tomar decisões mais embasadas. Destaca-se também, em particular, a contribuição para a área de estudos avaliação de políticas públicas estudantis, tendo em vista que o esforço da pesquisa possibilitou a criação de uma metodologia (apresentando as variáveis que devem ser medidas e como) para avaliações desse tipo de política.

\section{REFERÊNCIAS}

ANDRADE, Ana Maria Jung de. Desempenho acadêmico, permanência e desenvolvimento psicossocial de universitários: relação com indicadores de assistência estudantil. 2014. 57 f. Dissertação (Mestrado em Psicologia) - Universidade Federal do Rio Grande do Sul, Porto Alegre, 2014

BAGGI, C. A.; LOPES, D.A. Evasão e avaliação institucional no ensino superior: uma discussão bibliográfica. Avaliação, v. 16, n. 2, p.355-374, 2011. Disponível em: http://www.scielo.br/scielo.php?script=sci_arttext\&pid=S1414- 40772011000200007. Acesso em 10 de setembro de 2017.

BAMBERGER, Michael; TARSILLA, Michele; HESSE-BIBER, Sharlene. Why so many "rigorous" evaluations fail to identify unintended consequences of development programs: How mixed methods can contribute. Evaluation and Program Planning, v. 55, p. 155-162, 2016. Disponível $<$ http://dx.doi.org/10.1016/j.evalprogplan.2016.01.001>. Acesso em $02 \mathrm{de}$ maio de 2018.

BAMBERGER, Michael et al. American evaluation association professional development workshop real world e valuation and political constraints (extracted summary chapter). Jim Rugh, 2006.

BARROS, Silva Xavier. Expansão da educação superior no brasil: limites e possibilidades. Educ. Soc., Campinas v. 36, p. 361-390, 2010. Disponível em: < http://www.scielo.br/pdf/es/v36n131/1678-4626-es-36-131-00361.pdf $>$. Acesso em 16 de abril de 2017. 
BOLFARINE, Heleno; BUSSAB, Wilton O.; Elementos de amostragem. Porto Alegre: Bookman, 2005. $269 \mathrm{p}$

BRASIL, Decreto no 7.234, de 19 de julho de 2010. Dispõe sobre o Programa Nacional de Assistência Estudantil - PNAES. Diário Oficial da União, Seção 1, 20/7/2010, página 5. Disponível em: $<$ http://www.planalto.gov.br/ccivil 03/_ato2007-

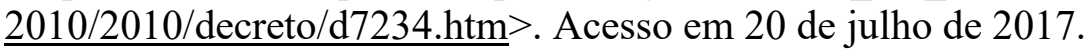

BRASIL, Ministério da Educação. Plano de Reestruturação e Expansão das Universidades Federais. 2007.

COSTA, F. L.; CASTANHAR, J. C. Avaliação de programas públicos: desafios conceituais e metodológicos. Revista de Administração Pública, v. 37, n. 22, p. 969-992, 2005.

Disponível em: $<$ http://bibliotecadigital.fgv.br/ojs/index.php/rap/article/viewArticle/6509>. Acesso em 20 de julho de 2017.

CUNHA, C. G. S. Avaliação de políticas públicas e programas governamentais: tendências recentes e experiências no Brasil. George Washington University, 2006. p. 1-41. Disponível em: < http://www.ufpa.br/epdir/images/docs/paper29.pdf >. Acesso em 21 maio de 2017.

FARIA, Ana Lucia Cosenza; FEIJÓ, Carmem Aparecida; SILVA, Denise Britz do Nascimento. Focalização de políticas públicas: uma discussão sobre os métodos de avaliação Ensaios FEE, Porto Alegre. p. 287-309, 2007. Disponível em: https://revistas.fee.tche.br/index.php/ensaios/article/view/2137/2521. Acesso em 20 julho de 2017.

FERREIRA, Pedro Lopes. Estatística descritiva e inferencial. Faculdade de Economia, Universidade de Coimbra p. 120, 2005. Disponível em:

$<$ https://estudogeral.sib.uc.pt/bitstream/10316/9961/1/AP200501.pdf $>$. Acesso em 20 setembro 2017.

FONAPRACE. Fórum Nacional de Pró-Reitores de Assuntos Estudantis e Comunitários. Plano Nacional de Assistência Estudantil. 2007.

FOLHA DE SÃO PAULO. Ranking Universitário Folha (RUF). Disponível em: http://ruf.folha.uol.com.br/2017/ranking-de-universidades/. Acesso em 13 de julho de 2018.

FREY, Klaus. Políticas públicas: um debate conceitual e reflexões referentes à prática da análise de políticas públicas no Brasil. Planejamento e Políticas Públicas, v. 21, p. 211-259, 2000 .

Disponível em: $<$ http://www.ipea.gov.br/ppp/index.php/PPP/article/view/89/158 $>$ Acesso em 20 de julho de 2017.

GIL, Antonio Carlos. Métodos e Técnicas de Pesquisa Social.-6.ed.- São Paulo: Atlas, 2008.

GIÚDICE, Junia Zacour Azevedo Del. Programa de Assistência Estudantil da

Universidade Federal de Viçosa, MG: repercussões nos indicadores acadêmicos e na vida pessoal, familiar e social dos beneficiários. Universidade Federal de Viçosa. Dissertação 
(mestrado), 2013.

IBGE. Instituto Brasileiro de Geografia e Estatística. Síntese de Indicadores Sociais, 2014. Disponível em: $<$ https://biblioteca.ibge.gov.br/visualizacao/livros/liv98965.pdf $>$. Acesso em 15 de agosto de 2017.

IMPERATORI, Kristosch. A trajetória da assistência estudantil na educação superior brasileira. Serv. Soc. Soc., São Paulo, p. 285-303, 2017.

KOWALSKI, Aline Viero. Os (des)caminhos da política de assistência estudantil e o desafio na garantia de direitos. 2012. 179 f. Tese (Doutorado em Serviço Social) Universidade Católica do Rio Grande do Sul, Porto Alegre, 2012.

MINAYO, Maria Cecília de Souza. Pesquisa social: teoria, método e criatividade. 28. ed. Petrópolis, RJ: Vozes, 2009. 108 p.

MPOG/SIOP - Site do Sistema Integrado de Planejamento e Orçamento do Governo Federal. Disponível em:

https://www1.siop.planejamento.gov.br/QvAJAXZfc/opendoc.htm?document=IAS\%2FExecu cao_Orcamentaria.qvw\&host $=$ QVS\%40pqlk04\&anonymous $=$ true $>$.Acesso em 20 de janeiro 2018 .

PATTON, Michael Quinn. The challenges of making evaluation useful. Ensaio: avaliação e políticas públicas em Educação, v. 13, n. 46, p. 67-78, 2005. Disponível em:

http://www.scielo.br/pdf/ensaio/v13n46/v13n46a04.pdf. Acesso em 20 de julho de 2017.

PATTON, Michael Quinn. Utilization-focused evaluation: the new century text. 3rd ed. Thousand Oaks, Calif.: Sage Publications, 1997.

PATTON, Michael Quinn. Utilization-focused evaluation checklist. The evaluation center Western Michigan University, n. January, p. 1-19, 2013. Disponível em:

$<$ http://www.wmich.edu/evalctr/wp-content/uploads/2010/05/UFE.pdf $>$. Acesso em: Acesso em 20 de julho de 2017.

PENHA, Joicy Barbalho Pires. Monitoramento e avaliação do Programa Nacional de Assistência Estudantil (PNAES) no âmbito da UFPE - Campus Vitória de Santo Antão. 2015. 185 f. Dissertação (Mestrado em Gestão Pública) - Universidade Federal de Pernambuco, Recife, 2015

RISTOFF, Dilvo. O Novo Perfil do Campus Brasileiro: Uma Análise do Perfil Socioeconômico. Avaliacao, Campinas, Sorocaba p.723-747, 2014.

RUA, Maria das Graças. Avaliaçao de politicas públicas. Políticas públicas. - 2. ed. reimp. Florianópolis: Departamento de Ciências da Administração / UFSC, 2012. 128 p.

SANTOS, Glauber Eduardo de Oliveira. Cálculo amostral: calculadora on-line. Disponível em: <http://www.calculoamostral.vai.la $>$. Acesso em 18 de abril de 2018.

SECCHI, Leonardo. Políticas Públicas: conceitos, esquemas de análise, casos práticos. São Paulo Cengage Learning, 2012. 
SERAPIONI, Mauro. Conceitos e métodos para a avaliação de programas sociais e políticas públicas. Sociologia, Revista da Faculdade de Letras da Universidade do Porto, v. 31, p. 59-80, 2016. Disponível em<

http://ojs.letras.up.pt/index.php/Sociologia/article/view/1461/1251 >. Acesso em 22 agosto de 2017.

SILVA, Maria Gabriela Queiroz da; EHRENBERG, Mônica Caldas. Atividades culturais e esportivas extracurriculares: influência sobre a vida escolar do discente. Pro-Posições, vol.28, n.1, pp.15-32, 2017. Disponível em:< http://www.scielo.br/pdf/pp/v28n1/1980-6248-pp-2801-00015.pdf $>$. Acesso em 10 de junho de 2018.

SIMÕES, Armando A. Avaliação de programas e políticas públicas. ENAP, 2015. Disponível em: $<$ file:///C:/Users/cleiton/Downloads/AVALIACAO-DE-PROGRAMAS-EPOLITICAS-PUBLICAS-003.pdf $>$. Acesso em 22 de agosto de 2017.

SOUZA, Celina. Políticas Públicas: uma revisão da literatura. Sociologias, Porto Alegre, ano 8, no 16, jul/dez 2006, p. 20-45. Disponível em: $<$ http://www.scielo.br/pdf/soc/n16/a03n16 $>$. Acesso em 15 de abril de 2017.

WEISS, Carol. Evaluation: methods for studying programs and policies. 2. ed. Upper Saddle River, NJ: Prentice Hall, 1998. 372 p.

WESKA, A.R.; SILVA, A. S.; ILIESCU, D. et al. Análise sobre a Expansão das Universidades Federais 2003 a 2012. Relatório da Comissão Constituiída pela Portaria $\mathrm{n}^{\mathrm{o}}$ 126/2012. Disponível em: < http://portal.mec.gov.br/index.php?option $=$ com docman\&view $=$ download\&alias $=12386$ analise-expansao-universidade-federais-2003-2012-pdf\&Itemid=30192>. Acesso em $20 \mathrm{de}$ abril de 2017.

$\mathrm{Wu}$, Xun et al. Guia de políticas públicas: gerenciando processos. Traduzido por Ricardo Avelar de Souza. Brasília: Enap, 2014. 